\title{
Effects of alcohol and extended practice on divided-attention performance
}

\author{
E. A. MAYLOR, P. M. A. RABBITT, G. H. JAMES, and S. A. KERR \\ Age and Cognitive Performance Research Centre, University of Manchester, Manchester, England
}

\begin{abstract}
The effects of alcohol and extended practice on divided attention were investigated using a visual tracking task and an auditory detection task. Subjects performed the tasks with and without alcohol, under single-task (S) and dual-task (D) conditions, both before and after they had received extended practice under single-task conditions without alcohol. Tracking accuracy improved with practice and was impaired under divided-attention conditions but was not affected by alcohol. Speed of detection was impaired by alcohol, improved by practice, and impaired by divided attention. Extended practice did not reduce the influence of alcohol. The effects of both alcohol and practice on speed of detection were significantly greater under dual-task conditions than under single-task conditions. Analysis of detection-task reaction times in terms of relative dividedattention costs, $(\mathrm{D}-\mathrm{S}) / \mathrm{S}$, showed no effect of alcohol, but a highly significant reduction in costs with extended practice. It is concluded that (1) alcohol and practice can have quantitatively, but not qualitatively, similar effects on speeded performance, and (2) the effect of alcohol is not influenced by the attentional requirements of the task.
\end{abstract}

A common strategy for research on the effects of alcohol has been to construct exhaustive catalogs of "components" of the human information-processing system that are, and are not, sensitive to its effects. The result has been that deficits have been proposed at almost every stage of information processing (Wallgren \& Barry, 1970). Many of the conclusions are based on marked interactions between alcohol and task complexity, which have been interpreted as the effect of alcohol on specific informationprocessing subsystems (e.g., Huntley, 1974).

However, recent work on the complexity effect, particularly in gerontology, has suggested that some caution is necessary in using this methodology to demonstrate localized effects (Cerella, 1985; Myerson, Hale, Wagstaff, Poon, \& Smith, in press; Salthouse, 1985). Thus, it is argued that many of the results interpreted as evidence for an effect on a specific mechanism could also be produced by a general mechanism, such as a generalized slowing of information-processing speed. If we assume that the absolute effect of alcohol upon performance increases with increased task complexity (which could perhaps be defined in terms of the number of mental operations presumed necessary to perform the task), it is clear that virtually any manipulation that produces a substantial increase in the level of task complexity will also result in an interaction between alcohol and that manipulation. Such an interaction might be interpreted as reflecting the

This research was supported by Medical Research Council of Great Britain, Grant G8221479N. The authors are grateful to Hal Pashler, Trammell Neill, and an anonymous reviewer for their helpful comments on an earlier version of the paper. Requests for reprints should be addressed to Elizabeth Maylor, Age and Cognitive Performance Research Centre, Oxford Road, Manchester M13 9PL, England. operation of alcohol upon some specific subprocess. But it could simply be that more complex tasks exhibit greater absolute differences between groups, regardless of the particular manipulation employed. In other words, the major determinant of the magnitude of most alcohol effects may be the complexity of the task, rather than its specific content.

Greater performance impairments under conditions of divided attention can be considered a manifestation of the complexity effect (Salthouse, 1982, 1985). Rather than concluding that, under alcohol, subjects are particularly poor at dividing attention, it could be argued that division of attention simply acts to increase the overall complexity of the situation, thereby involving a greater number of cognitive operations (e.g., Baron \& Mattila, 1989; McDowd \& Craik, 1988). It may be the case that decrements in performance due to alcohol would be as great in a single complex task as in two shared tasks.

Because driving a vehicle involves a complex coordinated sequence of perceptual and motor activities, most researchers seem to agree that "divided attention is one of the most valid methods to assess driving impairment caused by alcohol and drugs and is preferable to the use of simple visual motor tests ... or reaction times" (Landauer \& Howat, 1983, p. 648). Indeed, there have been many divided-attention studies involving alcohol (e.g., see Hamilton \& Copeman, 1970; Leigh, Tong, \& Campbell, 1977; MacAvoy \& Marks, 1975; Moskowitz, 1973; Moskowitz, 1984; Moskowitz, Burns, \& Williams, 1985; Moskowitz \& DePry, 1968; Moskowitz \& Smiley, 1982; Vuchinich \& Sobell, 1978). In all of these studies, the question arises as to what performance baseline should be used to assess alcohol effects under dual-task conditions. In some cases, performance was measured on only 
one of the two tasks; in others, the indices were not suitable for the examination of relative divided-attention costs, which represent one way of taking into account initial differences under single-task conditions. Thus, one of the aims of the present study was to investigate the effect of alcohol under single- and dual-task conditions, with reaction time (RT) as one of the dependent variables, such that dual-task scores could be assessed relative to each subject's single-task scores, as recommended by Somberg and Salthouse (1982).

The second issue of interest, namely practice, is related to the first "through the assumption that it reduces the complexity of a performance.... The question is whether a practiced performance is less susceptible to alcohol than before practice" (Seward \& Seward, 1936, p. 55). Jellineck and McFarland (1940) suggested that "within a task of given complexity, familiarity with the task tends to lower the effect of alcohol"' (p. 348). There have been several more recent attempts to investigate this (e.g., Jones, 1972; Tarter, Jones, Simpson, \& Vega, 1971).

Changes in performance with practice have been attributed to the development of automatic, resourceindependent processes (Schneider \& Shiffrin, 1977; Shiffrin \& Schneider, 1977) and to "shifts in the type of information being processed, in the identity or sequence of processing operations, and in the attention requirements of the task" (Salthouse \& Somberg, 1982, p. 176). Hasher and Zacks (1979) proposed a framework for research derived from Shiffrin and Schneider's (1977) distinction between automatic and effortful processes in which it was assumed that the total available attentional capacity varies both with states of an individual and between individuals. Since alcohol is thought to reduce attentional capacity or cognitive processing resources (Craik, 1977), this leads to the prediction that those under the influence of alcohol will show a greater decrease in performance on tasks requiring effortful processing (early in practice) than on tasks requiring less effortful and more automatic processing (late in practice). However, one difficulty with the alcohol studies published so far has been that they have not demonstrated that divided-attention performance has actually improved with practice. Thus, a second aim of the present study was to provide sufficient practice to establish qualitatively different performance levels (in terms of relative divided-attention costs) at which to compare the effects of alcohol.

\section{Experimental Design}

The present study investigated these issues by adopting the following design. The three independent variables of interest-namely, alcohol, practice, and divided attention-were all within-subjects factors. Subjects were tested both with alcohol and with no alcohol; the order of the two sessions was counterbalanced across subjects. Alcohol group and session were therefore entered into the analyses of variance as between- and within-subjects factors, respectively. A main effect of session would be evidence of a short-term practice effect from the first to the second session. Most importantly, an interaction between alcohol group and session would indicate an overall effect of alcohol.

To examine the influence of long-term practice, the two sessions were repeated, with the same alcohol order as before, after six intervening sessions during which subjects were given extensive practice on the single tasks without alcohol.

Finally, the effect of divided attention was investigated in the first two and final two sessions by comparing performance under single- and dual-task conditions.

\section{Experimental Tasks}

The tasks chosen in the present study were tracking and detection. We wished to avoid structural interference (Kahneman, 1973), which occurs when concurrent tasks require the use of the same specific perceptual or motor mechanisms. Thus, the tracking task was visual with a manual response, whereas the detection task required a foot response to auditory stimuli.

The tracking task allowed performance to be monitored continuously. The results of a pilot study involving subjects similar in age and intelligence to those in the main study allowed suitable parameters to be established such that the task was neither too difficult early in practice nor too easy late in practice (that is, floor and ceiling effects were avoided).

The detection task was chosen as a relatively undemanding task with a long history of use as an index of available attentional capacity (see Posner, 1978). Thus, performance could be measured on both tasks whether under single- or dual-task conditions.

\section{METHOD}

\section{Subjects}

Twenty-four male volunteers were recruited through advertisements placed around the University of Manchester and in local newspapers and shop windows. There were no teetotalers or excessive drinkers in the sample. The mean age was 20.5 years (standard deviation $=2.6$ ) and the mean weight was $70.6 \mathrm{~kg}$ (standard deviation $=9.2$ ). The subjects were tested at the same time each day from Monday to Friday of 2 consecutive weeks. Thus, each subject participated in 10 experimental sessions, which will hereafter be referred to as Days 1-10, although obviously Days 1-5 were separated from Days 6-10 by a weekend. The sessions on Days 1 , 2, 9, and 10 each lasted approximately $1 \mathrm{~h}$; those on Days 3-8 were $30 \mathrm{~min}$ in duration. Payment on completion of the experiment was $£ 20$ plus a $£ 1$ bonus for each day on which the subject was not more than 10 min late (maximum total payment $=\mathfrak{£ 3 0}$ ).

\section{Apparatus and Stimuli}

Alcohol was given in the form of vodka $(37.5 \%$ alcohol by volume) mixed with pure orange juice. A Lion Alcolmeter S-D2 (breathalyzer), obtained from Lion Laboratories Ltd., Barry, U.K., was used to estimate blood alcohol concentration to the nearest $5 \mathrm{mg}$ alcohol $/ 100 \mathrm{ml}$ blood.

The tracking and detection tasks were both controlled by BBC "Master" computers with Philips 80 monitors (green on black).

Visual tracking task. An Atari Quick Shot II deluxe joystick with a Computek BBC joystick interface (Model A-105A) controlled the movement on the screen of a cross measuring $11 \mathrm{~mm} \times 11 \mathrm{~mm}$. 
The joystick was operated by the subject's dominant hand and could be moved from its central position to one of eight positions ( $N$, NE, E, SE, S, SW, W, or NW), which enabled the cross to move in eight corresponding directions. The target was a regular octagon (12 mm diameter) that moved randomly around the screen (but never beyond it), also in eight directions. On average, it changed direction approximately every $1.33 \mathrm{sec}$. The cross and the target both moved at the same constant speed. However, when the fingercontrolled trigger button on the joystick was held down, the cross doubled its speed, and when the trigger was released, the cross returned to its original speed. This enabled the cross to "catch up" to the target when they became separated. Every $200 \mathrm{msec}$, the computer stored the current distance between the center of the cross and the center of the target (tracking error).

Auditory detection task. Single tones at $500 \mathrm{~Hz}$ were presented through the BBC speaker at almost the maximum volume. Each tone was presented until the subject responded. The response key was a hinged, sprung footswitch (RS 316-901) operated by the opposite foot to the dominant hand. The footswitch had to be released within $2 \mathrm{sec}$ after a response, otherwise an error was recorded. The RTs were measured to the nearest centisecond. The responsestimulus interval (RSI) was randomly varied between a minimum of $4 \mathrm{sec}$ and a maximum of $6 \mathrm{sec}$.

\section{Design and Procedure}

Prior to participation, the subjects were weighed and asked to complete a short questionnaire giving details of any current medication or serious illnesses and general drinking and smoking habits. In addition, they were required to sign a consent form agreeing to take part in the experiment and were warned not to drive, cycle, or handle dangerous machinery for $\mathbf{2 4} \mathrm{h}$ afterwards. They were also instructed to inform the experimenter of any side effects experienced as a result of the alcohol.

The subjects were tested individually. They were asked not to eat for at least $2 \mathrm{~h}$ before the testing sessions on Days 1, 2, 9, and 10 and not to drink alcohol on the previous evenings.

\section{Days $1,2,9$, and 10}

Half of the subjects received no alcohol (NA) on Days 1 and 9 and alcohol (A) on Days 2 and 10 (NA/A group); the other half received A on Days 1 and 9 and NA on Days 2 and 10 (A/NA group).

The procedure for Days 1, 2, 9, and 10 was almost exactly the same. First, a breath reading was taken. The subject was then given a 500-ml drink and was instructed to consume it within $5 \mathrm{~min}$. No information was provided concerning the contents of the drink. In the NA sessions, the drink was made up of $250 \mathrm{ml}$ pure orange juice, $250 \mathrm{ml}$ water, plus a few drops of vodka that were carefully floated on the top of the drink. In the A sessions, the drink contained $0.8 \mathrm{ml}$ alcohol per kilogram body weight and pure orange juice. The subject then waited for $10 \mathrm{~min}$, during which time reading material was available. On Day 1 only, some of this time was required for explaining the various tasks. For the next $10 \mathrm{~min}$, the subject was occupied by a letter-coding task (unrelated to the present study). A second breath reading was taken before the present experiment began. The tasks each lasted exactly $2 \mathrm{~min}$, and there was a 1-min break in between tasks. Half of the subjects performed the tasks in the following order: tracking, detection, detection, tracking, dual, dual, tracking, detection, detection, tracking. The tracking/ detection order was reversed for the other half of the subjects. A third breath reading was taken after the second dual task, and a fourth at the end of the session. Thus, the second, third, and fourth breath readings were obtained approximately 20,38 , and $50 \mathrm{~min}$, respectively, after finishing the drink.

The experimenter started and finished each task by pressing a key (or keys) on the computer keyboard(s). In all conditions (i.e., for both the single [tracking or detection] and the dual tasks), the subject was required to hold the joystick with his dominant hand, place the opposite foot on the footswitch, and look at the screen. The subject was seated with his eyes level with, and approximately $0.4 \mathrm{~m}$ away from, the center of the screen. The sound source for the detection task was slightly behind and to the left of the subject.

Tracking task (single). The subject was instructed to keep the cross as near to the center of the target as possible both by moving the joystick with the hand and by pressing the trigger button with the forefinger. The effects of these actions were fully explained.

Detection task (single). The subject was instructed that a tone would occur unpredictably every few seconds and that his task was to press the footswitch as soon as possible after hearing each tone, but not before. He was particularly warned against holding the footswitch down after making a response.

Concurrent tracking and detection (dual). In the dividedattention condition, the subject was required to perform the tracking and detection tasks simultaneously. Instructions were to give equal emphasis to the two tasks.

\section{Days 3-8}

The procedure for Days 3-8 was as follows. There was no drink and no letter-coding task. Each day began immediately with the appropriate tasks, each of which lasted exactly $3 \mathrm{~min}$, with a $1-\mathrm{min}$ break in between. There were no dual-task conditions. The subjects performed the single tasks in the same order as on Days 1 , 2,9 , and 10 .

\section{Data Analysis}

For the tracking-task data from Days 1, 2, 9, and 10, the mean tracking error was calculated for each 2-min run, excluding the last $5 \mathrm{sec}$ during which the experimenter was approaching to terminate the task. The mean was the average distance in computer units between the center of the cross and the center of the target; it represented 575 samples of relative cross and target positions.

For the detection task, because of the random RSI and the fact that each stimulus was presented for the duration of the RT, the number of tones in each 2 -min block was variable, with a mean of 23 (standard deviation $=0.7$ ). The first and last trials of each block were not included in the analysis. Because RT distributions are positively skewed, the median detection $R T$ was chosen as the performance measure. The number of errors was also recorded. These were defined as responses made between $2 \mathrm{sec}$ after the response to one stimulus and $50 \mathrm{msec}$ after the presentation of the next stimulus. Obviously, these include both errors of anticipation and errors caused by holding the footswitch down for more than $2 \mathrm{sec}$.

The data from Days 3-8 were not included in the analysis.

\section{RESULTS}

\section{Blood Alcohol Concentration}

The levels of alcohol in milligrams per $100 \mathrm{ml}$ blood estimated from the breathalyzer readings taken at the beginning of the sessions on Days 1, 2, 9, and 10 (prior to the drink) and 20,38 , and 50 min after the drink were all zero in the NA sessions. The means (and standard deviations) for the A sessions were $0.0(0.0), 59.6$ (19.2), 73.9 (18.7), and 77.3 (19.6). Note that the legal limit for driving in England is $80 \mathrm{mg}$ alcohol $/ 100 \mathrm{ml}$ blood.

\section{Tracking and Detection Tasks}

Performance in the detection task was highly accurate, with an overall mean error rate of only $0.8 \%$. The main performance measures were therefore the mean errors 


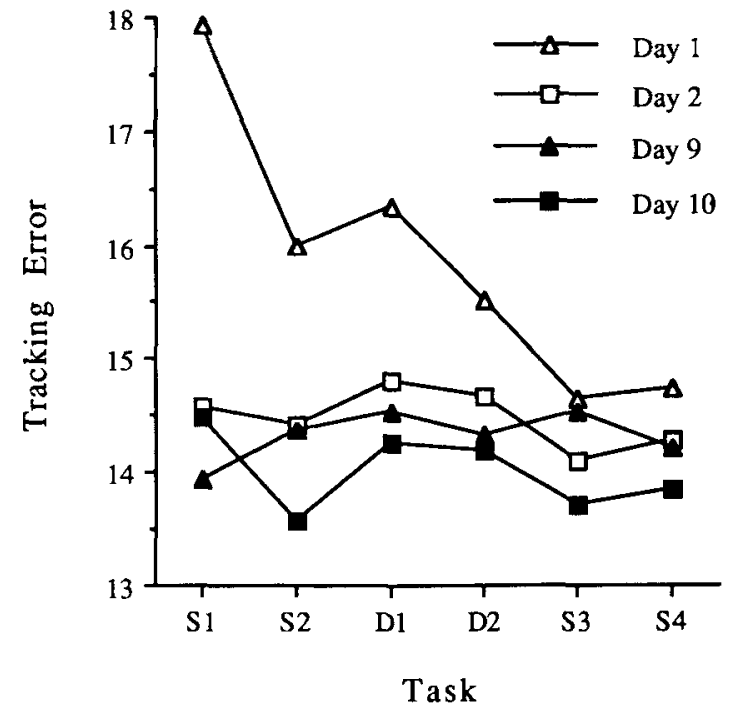

Figure 1. Overall mean tracking errors in arbitrary units averaged across all subjects for the four single-task (S1, S2, S3, and S4) and two dual-task (D1 and D2) conditions for each of Days 1, 2, 9, and 10.

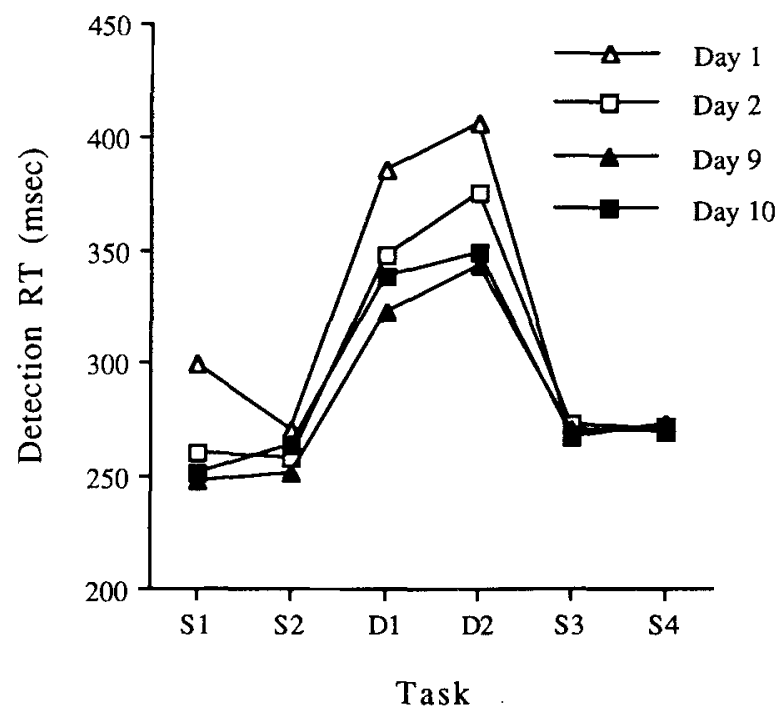

Figure 2. Overall median detection RTs in milliseconds averaged across all subjects for the four single-task (S1, S2, S3, and S4) and two dual-task (D1 and D2) conditions for each of Days 1, 2, 9, and 10.

from the tracking task and the median RTs from the detection task.

Figures 1 and 2 show the mean performance levels across all subjects in each task condition for Days 1,2 , 9 , and 10 on the tracking and detection tasks, respectively. Because of the particularly large practice effect between S1 and S2 on Day 1, the single task data for each day were summarized, in all of the following analyses, by the mean of $S 2$ and $S 3$ rather than by the mean of $S 1, S 2$,
S3, and S4. ${ }^{1}$ The dual-task data were summarized by the mean of D1 and D2.

The results were analyzed by four-way analyses of variance, with alcohol group ( 2 levels: NA/A and A/NA) as the between-subjects factor. The three within-subjects factors were: Day 19/2X (short-term practice), Day 12/9X (long-term practice), and $S / D$, each with two levels. Day 19/2X compared the first of the two days in each pair (i.e., Days 1 and 9) with the second of the two days in each pair (i.e., Days 2 and 10, with 10 denoted as X). Remember that an overall effect of alcohol would be indicated by an interaction between alcohol group and Day 19/2X. Day 12/9X compared the first pair of days (Days 1 and 2) with the last pair of days (Days 9 and 10 or X), that is, the effect of extended practice. Finally, S/D compared single-task performance with dual-task performance, in other words, an estimate of the effect of divided attention.

The results of the analyses of variance for the tracking and detection tasks are shown in Table 1. The data are also illustrated in Figures 3 and 4.

Performance in the tracking task (see Table 1 and Figure 3) was not significantly affected by alcohol (see effects numbered [3], [9], [11], and [15] in Table 1), but it did improve with practice, both from the first to the second day of each pair [2] and from the first two days to the last two days [4]. There was a highly significant divided-attention effect [6], which was not significantly reduced by practice $[10,12,14]$.

In contrast to tracking, performance in the detection task (see Table 1 and Figure 4) was highly significantly impaired by alcohol [3]. Note that the effect of alcohol did not decrease with practice $[9,15]$. However, the effect of alcohol was significantly greater in the dual condition than in the single condition [11]. Overall, RT decreased from $332 \mathrm{msec}$ on Day 1 to $313 \mathrm{msec}$ on Day 2 and to $297 \mathrm{msec}$ on Day 3, and then it increased slightly to

Table 1

Results of Analyses of Variance: $F$ Ratios $(d f=1,22)$ for Mean Tracking Errors and Median Detection RTs

\begin{tabular}{|c|c|c|c|}
\hline & Effect & Tracking & Detection \\
\hline [1] & Group & 0.78 & 0.01 \\
\hline [2] & $19 / 2 X$ & $8.20^{*}$ & 0.63 \\
\hline [3] & Group $\times 19 / 2 X$ & 1.54 & $13.31^{*}$ \\
\hline [4] & $12 / 9 \mathrm{X}$ & $5.15+$ & $10.22 *$ \\
\hline [5] & Group $\times 12 / 9 \mathrm{X}$ & 0.05 & 1.12 \\
\hline [6] & $\mathrm{S} / \mathrm{D}$ & $12.54^{*}$ & $149.07 \ddagger$ \\
\hline [7] & Group $\times S / D$ & 2.95 & 0.73 \\
\hline [8] & $19 / 2 X \times 12 / 9 X$ & 0.91 & $9.11 *$ \\
\hline [9] & Group $\times 19 / 2 X \times 12 / 9 X$ & 2.67 & 0.03 \\
\hline [10] & $19 / 2 \mathrm{X} \times \mathrm{S} / \mathrm{D}$ & 1.10 & $4.95+$ \\
\hline [11] & Group $\times 19 / 2 X \times S / D$ & 0.17 & $6.91 \dagger$ \\
\hline [12] & $12 / 9 X \times S / D$ & 2.11 & $24.96 \ddagger$ \\
\hline [13] & Group $\times 12 / 9 \mathrm{X} \times \mathrm{S} / \mathrm{D}$ & 0.85 & 1.96 \\
\hline [14] & $19 / 2 \mathrm{X} \times 12 / 9 \mathrm{X} \times \mathrm{S} / \mathrm{D}$ & $3.51 \S$ & $24.16 \ddagger$ \\
\hline [15] & Group $\times 19 / 2 X \times 12 / 9 X \times S / D$ & 0.03 & $0.06^{\circ}$ \\
\hline
\end{tabular}

Note-Group $=$ NA/A group vs. A/NA group; $19 / 2 X=$ short-term practice effect; $12 / 9 \mathrm{X}=$ long-term practice effect; $\mathrm{S} / \mathrm{D}=$ single task vs. dual task. ${ }^{*} p<.01 . \quad \dagger p<.05 . \quad \ddagger p<.001 . \quad \$ p<.1$. 


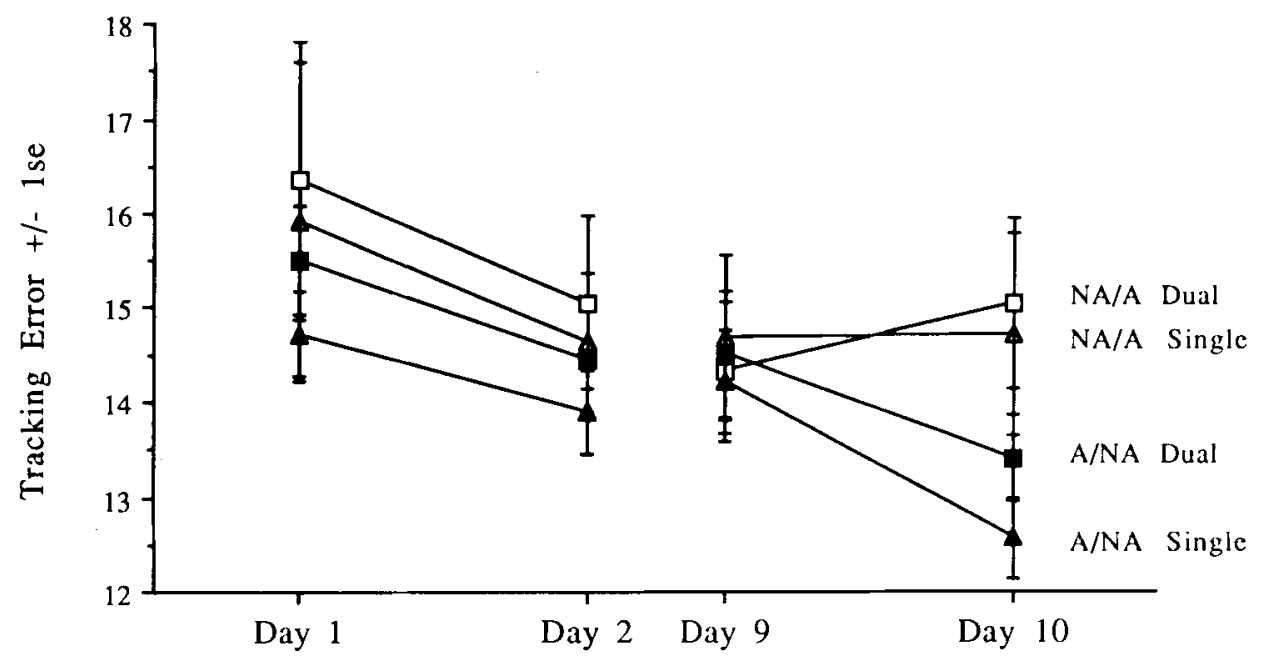

Figure 3. Mean tracking errors with standard error bars for the single- and dual-task conditions on Days 1, 2, 9, and 10, separately for the two alcohol groups (NA/A and A/NA).

$305 \mathrm{msec}$ on Day $10[4,8]$. The pattern was similar for the divided-attention effect [6], that is, the differences between single- and dual-task RTs were $126,95,71$, and $77 \mathrm{msec}$ on Days $1,2,9$, and 10 , respectively $[10,12$, 14].

\section{Relative Divided-Attention Costs}

For detection RT, the effects of both alcohol and practice were greater in the dual-task condition than in the single-task condition (see Table 1 and Figure 4). To take account of differences in single-task performance due to alcohol and practice, relative divided-attention costs were calculated, that is, the difference between dual- and singletask performance as a proportion of single-task performance: $(\mathrm{D}-\mathrm{S}) / \mathrm{S}$. These proportions were transformed using an arcsine transformation prior to analysis of variance with alcohol group, Day 19/2X (short-term practice), and Day 12/9X (long-term practice) as between-, within-, and within-subjects factors, respectively (see Table 2 ).

The difference between divided-attention costs with alcohol (0.36) and without alcohol (0.33) did not approach significance (Table 2, [3]). In contrast, divided-attention costs decreased with practice [4], at least until Day 9 [6]. The overall means for Days $1,2,9$, and 10 were 0.46 , $0.36,0.27$, and 0.29 , respectively.

\section{DISCUSSION}

Practice and divided attention had the expected effects on tracking performance, that is, the subjects improved

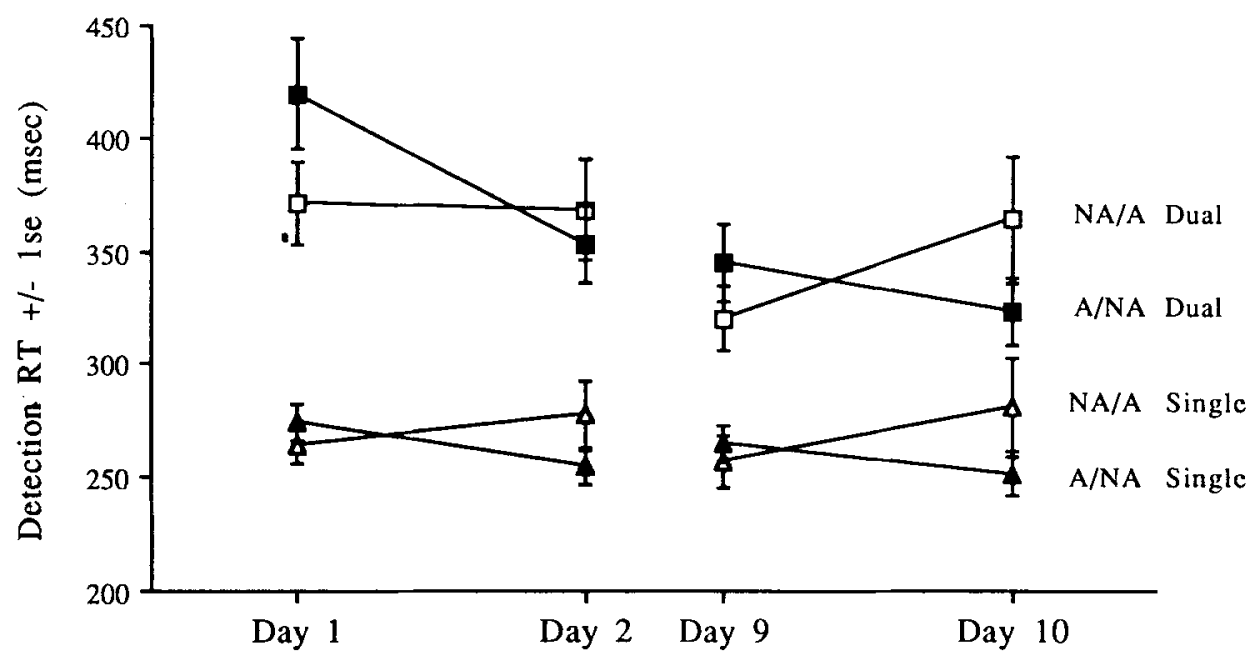

Figure 4. Median detection RTs with standard error bars for the single- and dual-task conditions on Days 1, 2, 9, and 10, separately for the two alcohol groups (NA/A and A/NA). 
Table 2

Results of an Analysis of Variance on the Arcsine-Transformed Relative Divided-Attention Costs in the Detection Task

\begin{tabular}{clc}
\hline \multicolumn{1}{c}{ Effect } & $F$ Ratio \\
\hline [1] & Group & 0.95 \\
{$[2]$} & $19 / 2 X$ & 2.49 \\
{$[3]$} & Group $\times 19 / 2 X$ & 1.38 \\
{$[4]$} & $12 / 9 X$ & $24.50^{*}$ \\
{$[5]$} & Group $\times 12 / 9 X$ & 2.19 \\
{$[6]$} & $19 / 2 X \times 12 / 9 X$ & $13.62 \dagger$ \\
[7] & Group $\times 19 / 2 X \times 12 / 9 X$ & 0.03 \\
\hline
\end{tabular}

Note-Group $=$ NA/A group vs. A/NA group; $19 / 2 X=$ short-term practice effect; $12 / 9 \mathrm{X}=$ long-term practice effect. For $F$ ratio, $d f=1,22 . \quad{ }^{*} p<.001 . \quad \dagger p<.01$.

with practice but were impaired under dual-task conditions. However, alcohol did not significantly impair performance in the tracking task. This is surprising for two reasons: (1) the task was not insensitive since it showed significant effects of both practice and divided attention, and (2) several studies in the literature have shown reliable effects of alcohol on tracking performance (e.g., Jellineck \& McFarland, 1940; Mortimer, 1963; Sturgis \& Mortimer, 1973). There appears to be no obvious explanation for this absence of an alcohol effect, although it should be noted that the present study employed a rather lower dose $(0.8 \mathrm{ml}$ per kilogram body weight) than is traditionally used $(1.0 \mathrm{ml}$ and above). At least the trend was in the expected direction (see Figure 3), ruling out the possibility that the adverse effect of alcohol on detection performance under dual-task conditions was associated with superior tracking performance.

The effects of the three factors of interest (alcohol, practice, and divided attention) were rather more dramatic in the detection task (compare the "Tracking" and "Detection" columns of Table 1). Note that, although the subjects were asked to give equal weighting to the two tasks, tracking may have been regarded as the primary task since it required almost continuous responding, in contrast to the detection task, which required continuous monitoring but on average only 23 responses during each 2 -min run.

In the detection task, the subjects were slower under dual-task conditions than under single-task conditions, as expected. The overall effects of alcohol and extended practice on detection RT were quantitatively similar, namely, an increase of $25 \mathrm{msec}$ with alcohol and a decrease of $22 \mathrm{msec}$ with practice (Days 1 and 2 to Days 9 and 10). The effects of alcohol and practice were also qualitatively similar in the sense that they were both significantly larger in the dual-task condition than in the single-task condition. This can be seen in Figure 5 in which the overall effects of alcohol and practice have been plotted separately for the single- and dual-task conditions. The crucial difference between alcohol and practice, which is partly illustrated by the interaction in Figure 5, was in terms of the relative divided-attention costs. These decreased considerably with extended practice but did not significantly increase with alcohol. In other words, although the absolute costs of divided attention were larger both with alcohol and early in practice, when initial differences in single-task performance were controlled by analyzing dual-task performance relative to single-task performance, only the effect of practice was significant. ${ }^{2}$

Using very similar tasks, Baddeley, Logie, Bressi, Della Sala, and Spinnler (1986) demonstrated that patients suffering from dementia of the Alzheimer type (DAT) are more dramatically impaired by a concurrent detection task than are controls "indicating that the DAT patients are more vulnerable to the demands of combining two tasks" (p. 615). However, the authors noted that since the DAT patients were worse than controls at the detection task under single-task conditions, it could be argued that the detection task was simply more difficult for the DAT patients than for the controls. Thus, their results "may simply indicate that adding a difficult task to tracking impairs performance more than adding an easier task"' (p. 615). The same argument could, of course, apply to the effect of alcohol in the present study, but the important point to stress is the contrast between alcohol and practice as illustrated in Figure 5. That is, the effect of alcohol was larger than the effect of practice in the single-task condition, whereas the reverse was the case in the dualtask condition.

With respect to extended practice, these results are consistent with those of McDowd (1986), who also found that divided-attention performance as measured by relative divided-attention costs improved over six experimental sessions. In addition, the findings provide further evidence in support of the conclusions of Maylor and Rabbitt (1989) and Maylor, Rabbitt, and Connolly (1989) regarding the contrasting effects of alcohol and practice on speeded performance. Although amounts of alcohol and practice can be manipulated to produce quantitatively similar overall effects, on closer examination it becomes clear that alcohol

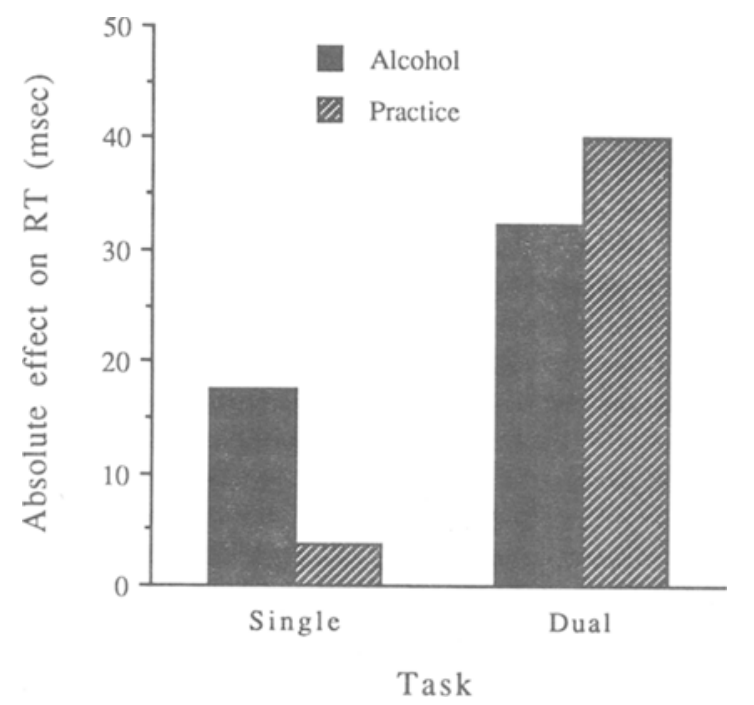

Figure 5. Graph summarizing the overall effects of alcohol and extended practice (i.e., the difference between Days 1 and 2 and Days 9 and 10) on detection RT, under single- and dual-task conditions. 
and practice alter performance in qualitatively different ways. Improvement with practice is, to some degree, associated with changes in control processes such as the ability to judge response speed (Maylor, Rabbitt, \& Connolly, 1989) and to coordinate two concurrent tasks by the central executive (as in the present study). In contrast, there is no evidence that alcohol impairs control processes in speeded tasks. Rather, alcohol simply slows information processing in the various conditions in proportion to baseline RT, so that RTs under alcohol can be derived from baseline RTs by multiplication by a simple constant (as in the present study; see also Maylor \& Rabbitt, 1987, 1989; Maylor, Rabbitt, James, \& Kerr, 1990). Thus, the results of these studies reinforce the methodological caveats discussed in the introduction to this paper. At the very least, they suggest that we should be wary of attributing all between- and within-subjects differences caused, for example, by old age, low intelligence, ingestion of alcohol, and early stages of practice to global deficits (e.g., Salthouse, 1985), such as "reduced processing resources" or "slower information processing" (see also Maylor, Rabbitt, James, \& Kerr, in press).

It must finally be emphasized that the absolute effect of alcohol was not reduced by extended practice, even though practice did significantly reduce the degree of involvement of attentional control (as indexed by the relative divided-attention costs). Thus, taken together with the results of Maylor and Rabbitt (1988) in which "almost identical effects of alcohol were observed for consistently mapped and variably mapped conditions" (p. 117), there is mounting evidence that the effect of alcohol is not influenced by the attentional requirements of the task.

\section{REFERENCES}

Baddeley, A., Logie, R., Bressi, S., Della Sala, S., \& Spinnler, H. (1986). Dementia and working memory. Quarterly Journal of Experimental Psychology, 38A, 603-618.

BARON, A., \& MATTILA, W. R. (1989). Response slowing of older adults: Effects of time-limit contingencies on single- and dual-task performances. Psychology \& Aging, 4, 66-72.

Cerella, J. (1985). Information processing rates in the elderly. Psychological Bulletin, 98, 67-83.

Craik, F. I. M. (1977). Similarities between the effects of aging and alcoholic intoxication on memory performance, construed within a 'levels of processing' framework. In I. M. Birnbaum \& E. S. Parker (Eds.), Alcohol and human memory (pp. 9-21). Hillsdale, NJ: Erlbaum.

Hamilton, P., Copeman, A. (1970). The effect of alcohol and noise on components of a tracking and monitoring task. British Journal of Psychology, 61, 149-156.

HASHER, L., \& ZACKs, R. T. (1979). Automatic and effortful processes in memory. Journal of Experimental Psychology: General, 108, 356-388.

HUNTLEY, M. S. (1974). Effects of alcohol, uncertainty and novelty upon response selection. Psychopharmacologia, 39, 259-266.

JELLINECK, E., \& MCFARLAND, R. (1940). Analysis of psychological experiments on the effects of alcohol. Quarterly Journal of Studies on Alcohol, 1, 272-371.

JONES, B. M. (1972). Cognitive performance during acute alcohol intoxication: The effects of prior task experience on performance. Psychonomic Science, 26, 327-329.

KahNEMAN, D. (1973). Attention and effort. Englewood Cliffs, NJ: Prentice-Hall.
Landauer, A. A., \& Howat, P. (1983). Low and moderate alcohol doses, psychomotor performance and perceived drowsiness. Ergonomics, 26, 647-657.

Leigh, G., Tong, J. E., \& Campbell, J. A. (1977). Effects of ethanol and tobacco on divided attention. Journal of Studies on Alcohol, $\mathbf{3 8}$, 1233-1239.

MacAvoy, M. G., MARKs, D. F. (1975). Divided attention performance of cannabis users and nonusers following cannabis and alcohol. Psychopharmacologia, 44, 147-152.

Maylor, E. A., RABbitt, P. M. A. (1987). Effects of alcohol and practice on choice reaction time. Perception \& Psychophysics, 42, 465-475

MAYLor, E. A. \& RABbitt, P. M. A. (1988). Amount of practice and degree of attentional control have no influence on the adverse effect of alcohol in word categorization and visual search tasks. Perception \& Psychophysics, 44, 117-126.

MAYlor, E. A., RABbitt, P. M. A. (1989). Relationship between rate of preparation for, and processing of, an event requiring a choice response. Quarterly Journal of Experimental Psychology, 41A, 47-62.

Maylor, E. A., RABbitT, P. M. A., \& ConNolly, S. V. (1989). Rate of processing and judgment of response speed: Comparing the effects of alcohol and practice. Perception \& Psychophysics, 45, 431-438.

Maylor, E. A., Rabbitt, P. M. A., James, G. H., \& Kerr, S. A. (in press). Comparing the effects of alcohol and intelligence on text recall and recognition. British Journal of Psychology.

Maylor, E. A., Rabbitt, P. M. A., James, G. H., \& Kerr, S. A. (1990). Effects of alcohol, practice and task complexity on reaction time distributions. Manuscript submitted for publication.

MCDowd, J. M. (1986). The effects of age and extended practice on divided attention performance. Journal of Gerontology, 41, 764-769.

MCDowd, J. M., \& CraIK, F. I. M. (1988). Effects of aging and task difficulty on divided attention performance. Journal of Experimental Psychology: Human Perception \& Performance, 14, 267-280.

Mortimer, R. G. (1963). Effect of low blood alcohol concentrations in simulated day and night driving. Perceptual \& Motor Skills, 17, 399-408.

Moskowitz, H. (1973). Laboratory studies of the effects of alcohol on some variables related to driving. Journal of Safety Research, 5 , 185-199.

Mosxowrtz, H. (1984). Attention tasks as skills performance measures of drug effects. British Joumal of Clinical Pharmacology, 18, 51S-61S.

Moskowitz, H., Burns, M. M., \& Williams, A. F. (1985). Skills performance at low blood alcohol levels. Journal of Studies on Alcohol, 46, 482-485.

Moskowitz, H., \& DEPrY, D. (1968). Differential effect of alcohol on auditory vigilance and divided-attention tasks. Quarterly Journal of Studies on Alcohol, 29, 54-63.

Moskowitz, H., \& SMileY, A. (1982). Effects of chronically administered buspirone and diazepam on driving-related skills performance. Journal of Clinical Psychiatry, 43, 45-55.

Myerson, J., Hale, S., Wagstaff, D., Poon, L. W., \& Smith, G. A. (in press). The information loss model: A mathematical theory of agerelated cognitive slowing. Psychological Review.

Posner, M. I. (1978). Chronometric explorations of mind. Hillsdale, NJ: Erlbaum.

SAlthouse, T. A. (1982). Adult cognition: An experimental psychology of human aging. New York: Springer-Verlag.

SAlthouse, T. A. (1985). A theory of cognitive aging. Amsterdam: North-Holland.

SAlthouse, T. A., \& Somberg, B. L. (1982). Skilled performance: Effects of adult age and experience on elementary processes. Journal of Experimental Psychology: General, 111, 176-207.

SChNeIder, W., \& ShIFfrin, R. M. (1977). Controlled and automatic human information processing: I. Detection, search and attention. Psychological Review, 84, 1-66.

Seward, G. H., SEWARd, J. P. (1936). Alcohol and task complexity. In R. S. Woodworth (Ed.), Archives of psychology, No. 206, New York.

Shiffrin, R. M., SchNeider, W. (1977). Controlled and automatic human information processing: II. Perceptual learning, automatic attending, and a general theory. Psychological Review, 84, 127-190. 
Somberg, B. L., SAlthouse, T. A. (1982). Divided attention abilities in young and old adults. Journal of Experimental Psychology: Human Perception \& Performance, 8, 651-663.

Sturgis, S. P., Mortimer, R. G. (1973). Effects of practice and alcohol on selected skills: Implications for an automobile alcohol ignition interlock. Perceptual \& Motor Skills, 37, 267-274.

TArter, R. E., Jones, B. M., Simpson, C. D., \& Vega, A. (1971). Effects of task complexity and practice on performance during acute alcohol intoxication. Perceptual \& Motor Skills, 33, 307-318.

WAllgren, H., BARRY, H., III (1970). Actions of alcohol. New York: Elsevier.

VUCHINICH, R. E., \& SoBELL, M. B. (1978). Empirical separation of physiologic and expected effects of alcohol on complex perceptual motor performance. Psychopharmacology, 60, 81-85.

\section{NOTES}

1. In a similar task, Somberg and Salthouse (1982, experiment 2) also noted a "sizeable practice effect" between the first and second blocks and therefore excluded the first and final blocks (to retain counterbalancing) from the analyses.

2. It should be noted that while there may be debate over whether or not relative divided-attention costs provide a perfect method for "partialling out" single-task differences in assessing dual-task differences, the present emphasis is on the contrast between the effects of alcohol and practice on this measure of divided-attention performance.

(Manuscript received March 27, 1990; revision accepted for publication June 11,1990 .)

\title{
Wang Institute of Boston University Tyngsboro, Massachusetts
}

\author{
Neural Networks: From Foundations to Applications \\ A Self-Contained Course \\ May 5-10, 1991
}

This self-contained 5-day course, sponsored by the Boston University Wang Institute, Center for Adaptive Systems, and Graduate Program in Cognitive and Neural Systems, refines and updates the successful course held at the Wang Institute in May 1990. The course provides a systematic interdisciplinary introduction to the biology, computation, mathematics, and technology of neural networks. Boston University tutors are Dan Bullock, Gail Carpenter, Michael Cohen, Stephen Grossberg, John Merrill, and Ennio Mingolla. Guest tutors are Andy Barto, Federico Faggin, Robert Hecht-Nielsen, Michael Jordan, and Alex Waibel. The Wang Institute lies on a 220-acre campus with excellent conference and dining facilities, easily reached from Boston's Logan Airport.

Registration fees: $\$ 985$ (professionals) and $\$ 275$ (students). Fee includes lectures, course notebooks, receptions, meals, coffee services, and evening discussion sessions. To register by phone, call (508) 649-9731 with VISA or MasterCard between 9 a.m. and 5 p.m. (EST). For a course brochure, call as above or write: Neural Networks, Wang Institute of Boston University, 72 Tyng Road, Tyngsboro, MA 01879.

\section{Neural Networks for Vision and Image Processing A Research Conference May 10-12, 1991}

This research conference will present invited lectures and contributed posters ranging from visual neurobiology and psychophysics through computational modeling and technological applications. The conference is sponsored by the Boston University Wang Institute, Center for Adaptive Systems, and Graduate Program in Cognitive and Neural Systems with partial support from AFOSR. Invited speakers include: J. Beck, G. A. Carpenter, D. Casasent, J. Daugman, R. Desimone, S. Grossberg, R. Hecht-Nielsen, R. Linsker, E. Mingolla, A. Pentland, V. S. Ramachandran, E. Schwartz, G. Sperling, J. Todd, and A. Waxman.

A featured Poster Session will be held on May 11. To present a poster, submit three copies of an abstract (one single-spaced page), postmarked by March 1, 1991, for refereeing. Include with the abstract the author's name, address, and telephone number. Mail to VIP Poster Session, Neural Networks Conference, Wang Institute of Boston University, 72 Tyng Road, Tyngsboro, MA 01879. Authors will be informed of abstract acceptance by March 31, 1991.

Registration fees: $\$ 95$ (professionals) and $\$ 75$ (students). Fee includes lectures and poster session, reception, meals, and coffee services. To register by phone, call (508)649-9731 with VISA or MasterCard between 9 a.m. and 5 p.m. (EST). For a meeting brochure, call as above or write: Neural Networks, Wang Institute of Boston University, 72 Tyng Road, Tyngsboro, MA 01879. 